\title{
Ehrlichia sp. infection in carthorses of low-income owners, Southern Brazil
}

\author{
Thállitha S. Vieira ${ }^{\mathrm{a}, \mathrm{b}}$, Rafael F. Vieira ${ }^{\mathrm{b}}$, Felipe S. Krawczak ${ }^{\mathrm{c}}$, Herbert S. Soares ${ }^{\mathrm{c}}$, \\ Ana M. Guimarães ${ }^{c}$, Ivan R. Barros-Filho ${ }^{b}$, Mary Marcondes ${ }^{\mathrm{d}}$, Marcelo B. Labruna ${ }^{\mathrm{c}}$, \\ Alexander W. Biondo ${ }^{\mathrm{b}}$, Odilon Vidotto ${ }^{\mathrm{a}, *}$ \\ a Department of Preventive Veterinary Medicine, College of Veterinary Medicine, Universidade Estadual de Londrina, Londrina, PR, 86051-990, Brazil \\ ${ }^{\mathrm{b}}$ Department of Veterinary Medicine, Universidade Federal do Paraná, Curitiba, PR, 80035-050, Brazil \\ ${ }^{\mathrm{c}}$ Department of Preventive Veterinary and Animal Health, College of Veterinary Medicine, University of São Paulo, São Paulo, SP, 05508-270, Brazil \\ d Department of Clinics, Surgery and Animal Reproduction, College of Veterinary Medicine, São Paulo State University at Araçatuba, SP, 16050-680, Brazil
}

\section{A R T I C L E I N F O}

\section{Article history:}

Received 12 January 2016

Received in revised form 15 June 2016

Accepted 8 July 2016

\section{Keywords:}

Vector-borne disease

Tick-borne disease

Ehrlichiosis

\begin{abstract}
A B S T R A C T
Although well established in dogs, Ehrlichia sp. infection has been scarcely reported in horses. The aim was to perform a comprehensive serological and molecular survey for the detection of Ehrlichia spp. in carthorses from Southern Brazil. Blood samples from 190 carthorses from Paraná State were sampled. Horses were also tested for Borrelia burgdorferi and Anaplasma phagocytophilum. Anti-Ehrlichia sp. antibodies were detected by a commercial rapid ELISA, and immunofluorescence antibody assays (IFA) with $E$. chaffeensis and $E$. canis as crude antigens. The molecular and phylogenetic analysis of Ehrlichia sp. was based on $16 \mathrm{~S}$ rRNA and $d s b$ genes. A total of $52(27.4 \%), 4(2.1 \%)$, and $3(1.6 \%)$ horses were positive for Ehrlichia spp., Anaplasma spp. and Borrelia burgdorferi, respectively, by the commercial rapid ELISA. Thirty-eight (20.0\%) and 37 (19.5\%) horses showed anti-E. chaffeensis and anti-E. canis antibodies by IFA, respectively. One blood sample that also showed anti-E. chaffeensis antibodies was PCR positive for the $16 \mathrm{~S}$ rRNA and $d s b$ genes of Ehrlichia spp., showing an identity of $>98.0 \%$ to the uncultured Ehrlichia sp. previously detected in Brazilian jaguars (Panthera onca). Anti-Ehrlichia sp. antibodies and Ehrlichia DNA were detected in carthorses from Southern Brazil, which may post public health concerns due to intimate contact with low-income owners. This is the first report of a natural infection of this bacteria in horses from South America. Clinical signs and the tick vector remain unknown.
\end{abstract}

(c) 2016 Published by Elsevier Ltd.

\section{Introduction}

Ehrlichioses are tick-borne diseases affecting animals and human beings worldwide and caused by at least six bacterial species of the genus Ehrlichia: E. canis, E. chaffeensis, E. ewingii, E. muris, E. ruminantium and E. mineirensis [1,2]. Among domestic animals, the disease has been extensively studied in dogs, but mostly neglected in other animal species. In horses, few studies have described the presence of anti-Ehrlichia spp. antibodies in serum samples [3-6], and one potentially new Ehrlichia species has been described infecting horses from Nicaragua [5].

\footnotetext{
* Corresponding author at: Departamento de Medicina Veterinária Preventiva, Universidade Estadual de Londrina, Rodovia Celso Garcia Cid, Pr 445, Km 380. Campus Universitário, 86051-990, Londrina, Paran\&\#x00E1 Brazil.

E-mail address: vidotto@uel.br (O. Vidotto).
}

In Brazil, E. canis is the main Ehrlichia species found, widely spread in dogs throughout the country [7]. Other identified species include E. chaffeensis in marsh deer [8], a possible infection by $E$. ewingii in dogs [9], Ehrlichia sp. in a jaguar (Panthera onca) [10], and E. chaffeensis-like [11] and Ehrlichia sp. fox-ES1 [12] in crab-eating foxes (Cerdocyon thous). Despite the fact that horses in Brazil are frequently exposed to ticks [13] and are infected by other tick-borne agents [6,14,15], no molecular survey of Ehrlichia species infection has been reported to date in such species, particularly in horses with intimate contact with owners. Accordingly, the aim of this study was to perform a comprehensive serological and molecular survey for the detection of Ehrlichia spp. in carthorses from low-income owners of Southern Brazil. 


\section{Material and methods}

\subsection{Samples}

Blood samples from 190 carthorses previously surveyed for other pathogens $[15,16]$ from low-income owners of Alvorada do Sul $\left(22^{\circ} 54^{\prime} 34.4^{\prime \prime}\right.$ S 51 $\left.13^{\prime} 49.1^{\prime \prime} \mathrm{W}\right)$, Colombo $\left(25^{\circ} 25^{\prime} 47^{\prime \prime} \mathrm{S}\right.$ $\left.49^{\circ} 16^{\prime} 19^{\prime \prime} \mathrm{W}\right)$, Pinhais ( $\left.25^{\circ} 26^{\prime} 41^{\prime \prime} \mathrm{S} 49^{\circ} 11^{\prime} 33^{\prime \prime} \mathrm{W}\right)$ and Curitiba $\left(25^{\circ} 25^{\prime} 47^{\prime \prime} \mathrm{S} 49^{\circ} 16^{\prime} 19^{\prime \prime} \mathrm{W}\right)$ counties, Paraná state, Southern Brazil was included in this study. All serum and EDTA-blood samples were stored at $-80^{\circ} \mathrm{C}$ until serological and molecular procedures were performed. This study was approved by the Ethics Committee in Animal Experimentation and Animal Welfare at the Universidade Estadual de Londrina (protocol number 34/2011) and the Universidade Federal do Paraná (protocol number 027/2010), Paraná State, Brazil.

\subsection{Detection of antibodies against Anaplasma spp., Borrelia} burgdorferi sensu stricto and Ehrlichia spp. by ELISA

All carthorse serum samples were initially tested for antibodies against Anaplasma spp. (A. phagocytophilum and A. platys), B. burgdorferi sensu stricto (s.s.), and Ehrlichia spp. (E. canis and E. chaffeensis) using a commercial rapid ELISA test (SNAP ${ }^{\circledR} 4 \mathrm{Dx}^{\circledR}$, IDEXX Laboratories Inc., Westbrook, ME, USA), according to the manufacturer's instructions. Although this rapid screening ELISA test has been developed for canine samples [17], the antigen-specific conjugate has been previously validated $[18,19]$ and used for horse samples $[3,5,6]$.

\subsection{Detection of anti-Ehrlichia spp. antibodies by indirect immunofluorescent assay}

Anti-Ehrlichia spp. antibodies in carthorse serum samples were tested by indirect immunofluorescent assay (IFA) using E. canis (São Paulo strain) and E. chaffeensis (Arkansas strain) as antigens, as previously described [6]. Samples were considered positive when reacting with dilution $\geq 1: 64$. Endpoint titers were determined to the largest dilution in which fluorescence was visualized around the bacteria.

\subsection{DNA extraction}

DNA was extracted from $200 \mu \mathrm{L}$ of whole blood samples using a commercial kit (Illustra Blood genomicPrep Mini Spin Kit, GE Healthcare, Chalfont, St. Giles, UK), according to the manufacturer's instructions. Ultra-pure water was used as negative control to monitor for cross-contamination in each batch of 30 samples.

\subsection{PCR assays and DNA sequencing}

A PCR for the horse housekeeping gene, glyceraldehyde-3phosphate dehydrogenase (GAPDH), was performed to ensure successful DNA extraction, as previously described [20]. Samples were evaluated using conventional PCR with genus-specific previously described primers targeting a portion of the Ehrlichia $16 \mathrm{~S}$ rRNA (344 bp) [21] and disulfide bond formation protein gene ( $d s b$ ) (349 bp) [12]. PCR products of the expected size for each assay were purified from the gel and amplicons sequenced in both directions using the same PCR primers (forward and reverse) by Sanger sequencing.

\subsection{Phylogenetic analysis}

The generated partial sequence of the $d s b$ gene was aligned with sequences from GenBank database using MUSCLE [22].

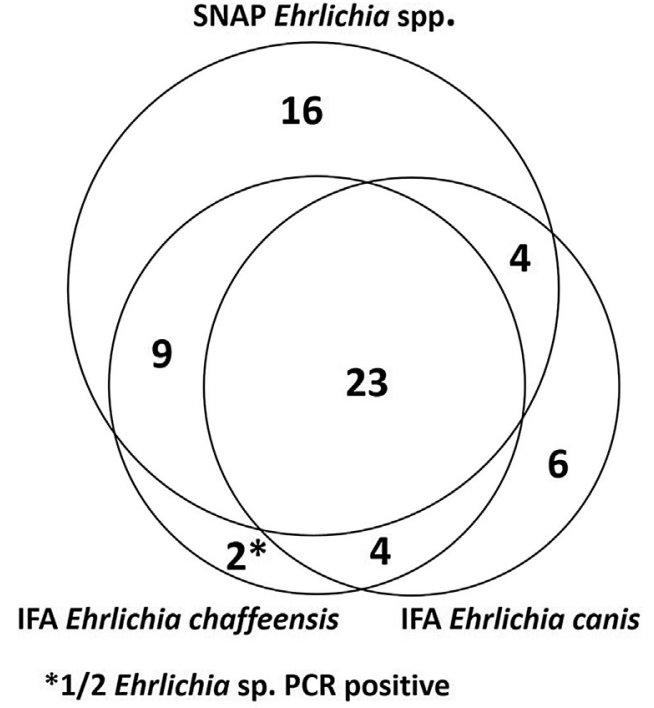

Fig. 1. Proportional Venn diagram showing cross-reactivity by commercial rapid ELISA test (SNAP) and IFA (E. canis and E. chaffeensis antigens). The diagram was generated by a program available at http://www.cmbi.ru.nl/cdd/biovenn/.

Phylogenetic trees were constructed using the neighbor-joining and maximum-likelihood methods. The Kimura two-parameter method was combined with the neighbor-joining method to correct for nucleotide substitutions. For both methods, data set was resampled 1000 times to generate bootstrap percentages. An available software [23] was used for analyses and the nucleotide sequence of the Ehrlichia $d s b$ gene amplified herein was submitted to GenBank database [GenBank: KT148966].

\subsection{Statistical analysis}

A database was generated and analyzed in a freely available software (Epi Info ${ }^{\mathrm{TM}}$ 7.5.1.0, CDC, Atlanta, USA). The Chi-square or Fisher's exact test was used to determine if individual factors (place, presence of ticks, age, or gender) were associated with seropositivity to Ehrlichia spp. Odds ratio (OR), 95\% confidence interval, and $p$ values were calculated separately for each variable. Results were considered significantly different when $p<0.05$.

The kappa coefficient $(\kappa)$ of agreement among the serological tests were calculated using a freely available software [24]. The magnitude of $\kappa$ coefficients was interpreted as follows: $\leq 0$ poor, 0.01-0.2 slight, $0.21-0.4$ fair, $0.41-0.6$ moderate, $0.61-0.8$ substantial, and 0.81-1 almost perfect agreement [25].

\section{Results}

Seroprevalence values for Ehrlichia spp., Anaplasma spp., and $B$. burgdorferi by the commercial rapid ELISA and E. canis and E. chaffeensis by IFA are shown in Table 1. A total of 64 (33.7\%) carthorses showed antibodies against at least one of the Ehrlichia spp. antigens (Ehrlichia canis Outer Membrane Protein, and E. canis and E. chaffeensis crude antigens), the majority $(52 / 64 ; 81.2 \%)$ being positive by the commercial rapid ELISA. Overlapping to different Ehrlichia spp. antigens were also comprehensively analyzed (Fig. 1). Antibody titers by IFA ranged from 1:64 to 1:8192 using E. canis antigen and from 1:128 to 1:4096 using E. chaffeensis antigen. The seroprevalence of Ehrlichia spp. in carthorses based on E. chaffeensis antigen within each variable evaluated is summarized in Table 2.

Degree of agreement was moderate $(k=0.491,95 \% \mathrm{CI}$ : 0.352-0.630) between the commercial rapid ELISA test and IFA with $E$. canis antigen, substantial $(k=0.624,95 \% \mathrm{CI}: 0.485-0.763)$ 
Table 1

Anti-Ehrlichia spp. antibodies by commercial rapid ELISA test and IFA in horses from Southern Brazil.

\begin{tabular}{|c|c|c|c|c|c|c|c|c|c|c|}
\hline \multirow{3}{*}{ Place } & \multicolumn{6}{|l|}{ Rapid ELISA } & \multicolumn{4}{|l|}{ IFA } \\
\hline & \multicolumn{2}{|l|}{ Ehrlichia spp. } & \multicolumn{2}{|c|}{ Anaplasma spp. } & \multicolumn{2}{|c|}{ Borrelia burgdorferi } & \multicolumn{2}{|l|}{ E. canis } & \multicolumn{2}{|l|}{ E. chaffeensis } \\
\hline & $+/ \mathrm{N}(\%)$ & $95 \% \mathrm{CI}$ & $+/ \mathrm{N}(\%)$ & $95 \% \mathrm{CI}$ & $+/ \mathrm{N}(\%)$ & $95 \% \mathrm{CI}$ & $+/ \mathrm{N}(\%)$ & $95 \% \mathrm{CI}$ & $+/ \mathrm{N}(\%)$ & $95 \% \mathrm{CI}$ \\
\hline Alvorada do Sul & $25 / 34(73.5)$ & $55.6-87.1$ & $0 / 34(0)$ & $0-10.3$ & $3 / 34(8.8)$ & $1.9-23.7$ & $19 / 34(55.9)$ & $37.9-72.9$ & $18 / 34(52.9)$ & $35.1-70.2$ \\
\hline Colombo & $11 / 49(22.4)$ & $11.8-36.6$ & $4 / 49(8.2)$ & $2.3-19.6$ & $0 / 49(0)$ & $0-7.3$ & $8 / 49(16.3)$ & $7.3-29.7$ & $11 / 49(22.4)$ & $11.8-36.6$ \\
\hline Pinhais & $14 / 87(16.1)$ & $9.1-25.5$ & $0 / 87(0)$ & $0-4.2$ & $0 / 87(0)$ & $0-4.2$ & $7 / 87(8.0)$ & $3.3-15.9$ & $6 / 87(6.9)$ & $2.6-14.4$ \\
\hline Curitiba & $2 / 20(10.0)$ & $1.2-31.7$ & $0 / 20(0)$ & $0-16.8$ & $0 / 20(0)$ & $0-16.8$ & $3 / 20(15.0)$ & $3.2-37.9$ & $3 / 20(15.0)$ & $3.2-37.9$ \\
\hline Total & $52 / 190(27.4)$ & $21.5-34.7$ & $4 / 191(2.1)$ & $0.6-5.3$ & $3 / 191(1.6)$ & $0.3-4.5$ & $37 / 190(19.5)$ & $14.1-25.8$ & $38 / 190(20.0)$ & $14.6-26.4$ \\
\hline
\end{tabular}

+ , Number of positive animals; N, number of samples per place; $95 \%$ CI, 95\% confidence interval.

Table 2

Anti-Ehrlichia spp. antibodies by IFA (E. chaffeensis) in horses within each variable studied.

\begin{tabular}{|c|c|c|c|c|}
\hline Variable & $+/ \mathrm{N}(\%)$ & OR & $95 \% \mathrm{CI}$ & $p$-value \\
\hline \multicolumn{5}{|l|}{ Place } \\
\hline Alvorada do Sul & $18 / 34(52.9 \%)$ & 6.37 & $1.57-25.85$ & 0.0057 \\
\hline Colombo & $11 / 49(22.4 \%)$ & 1.64 & $0.4-6.6$ & 0.3665 \\
\hline Pinhais & $6 / 87(6.9 \%)$ & 0.42 & $0.09-1.8$ & 0.2213 \\
\hline Curitiba & $3 / 20(15 \%)$ & Ref. & & \\
\hline \multicolumn{5}{|l|}{ Presence of Ticks } \\
\hline Yes & $16 / 41(39 \%)$ & 3.69 & $1.7-8.0$ & 0.0005 \\
\hline No & $22 / 149(14.8 \%)$ & Ref. & & \\
\hline \multicolumn{5}{|l|}{ Age (Years) } \\
\hline$>10$ & $12 / 34(26.1 \%)$ & 0.72 & $0.30-1.6$ & 0.4505 \\
\hline $5-10$ & $16 / 79(20.3 \%)$ & 1.13 & $0.4-2.8$ & 0.7936 \\
\hline$<5$ & $9 / 49(23.4 \%)$ & Ref. & & \\
\hline \multicolumn{5}{|l|}{ Gender } \\
\hline Female & $21 / 88$ (23.9\%) & 1.56 & $0.7-3.2$ & 0.2162 \\
\hline Male & $17 / 102(16.7 \%)$ & Ref. & & \\
\hline
\end{tabular}

+, Number of positive animals; N, number of samples per variable; OR, odds ratio; $95 \% \mathrm{CI}, 95 \%$ confidence interval; Ref. variable used as a reference value.

between the commercial rapid ELISA test and IFA with E. chaffeensis antigen, and substantial ( $k=0.6512,95 \%$ CI: 0.509-0.793) between the IFA with E. canis and IFA with E. chaffeensis antigens.

All carthorse DNA samples consistently amplified the GAPDH gene, ensuring successful DNA extraction. Only 1/190 (0.5\%; 95\% CI: $0.0-2.9 \%$ ) sample has yielded amplicons of the expected size for the Ehrlichia $16 \mathrm{~S}$ rRNA and $d s b$ genes by PCR. This animal was seropositive to E. chaffensis by IFA only, with a titer of 1:512. Sequencing of the 16S rDNA fragment (306 bp) showed that this gene region is $98-99 \%$ identical to all five Ehrlichia species described to date and up to $100 \%$ identical to multiple other Ehrlichia spp. genotypes deposited in GenBank. Although results confirmed the detection of Ehrlichia sp. in carthorses, proper sequence discrimination for phylogenetic analysis solely based in this gene fragment was not possible.

DNA sequence obtained from the Ehrlichia sp. dsb gene (307 bp) has shown variable degrees of divergence with gene sequences deposited in GenBank. Sequence was closest related to two Brazilian native species: uncultured Ehrlichia sp. clone J6 (98.0\%; 301/307; HQ388287) from free-ranging jaguars (Panthera onca) of the Central-Western region [10] and uncultured Ehrlichia sp. clone F2 (84.0\%; 254/303; KC127678) from crab-eating fox (Cerdocyon thous) of the Southeastern region [12]. In addition, closest identity was also observed with Ehrlichia ruminantium (82.0\%; 249/305; CR925678) from South Africa [26].

Phylogenetic $d s b$ gene fragment analysis confirmed the close relationship of the horse ehrlichial genotype of the present study with the uncultured Ehrlichia sp. clone J6 detected in Brazilian jaguars, under $>99 \%$ bootstrap support. Both genotypes formed a strongly supported clade of $>92 \%$ bootstrap with the Ehrlichia sp. detected in crab-eating fox and E. ruminantium (Fig. 2).

\section{Discussion}

To the authors' knowledge, this is the first report of a natural Ehrlichia sp. infection in horses from South America, a likely infection confirmed by DNA detection and sequencing, associated to an antibody titer of 1:512 by IFA with $E$. chaffeensis crude antigen.

Actually, Ehrlichia sp. infecting horses was only reported in Nicaragua, Central America, with a novel species revealed by $16 \mathrm{~S}$ rRNA, $\operatorname{sodB}$, and groEL sequencing and gene analysis [5]. Since studies have sequenced different genes and different $16 \mathrm{~S}$ rRNA regions, whether the Ehrlichia sp. found herein is the same infecting horses in Nicaragua or a novel species remains to be further determined. Interestingly, although with different sequence alignments, both strains have similarly been placed in the E. ruminantium (CR925678) clade in Neighbor-Joining and Maximum Likelihood phylogenetic trees (Fig. 2). When compared to similar studies, partial 16S rRNA sequence in the present study has shown $100 \%$ identity with multiple other Ehrlichia spp. found in ticks from Asia (KJ410253, HQ697589, AY30997, KF728356, GU075696, and GU0756981). Partial $d s b$ gene sequence has revealed Ehrlichia species closely related to previously reported in Brazilian freeranging jaguars (Fig. 2).

In addition to molecular findings, carthorses from Southern Brazil may be highly exposed to Ehrlichia spp. infection. This fact is supported since anti-Ehrlichia spp. antibodies were detected by two independent serological methods (ELISA and IFA) using three different Ehrlichia antigens [p30/p30-1 outer membrane proteins (OMPs) of E. canis, and crude antigens of E. canis and E. chaffeensis], as shown on Venn diagram (Fig. 1). However, it is important to note that serological methods may yield false-positive results because these techniques do not differentiate between infection and previous exposure to Ehrlichia sp. On the other hand, only one horse was found to be infected by Ehrlichia sp. in the present study. This found may be explained by the fact that false-negative results by 

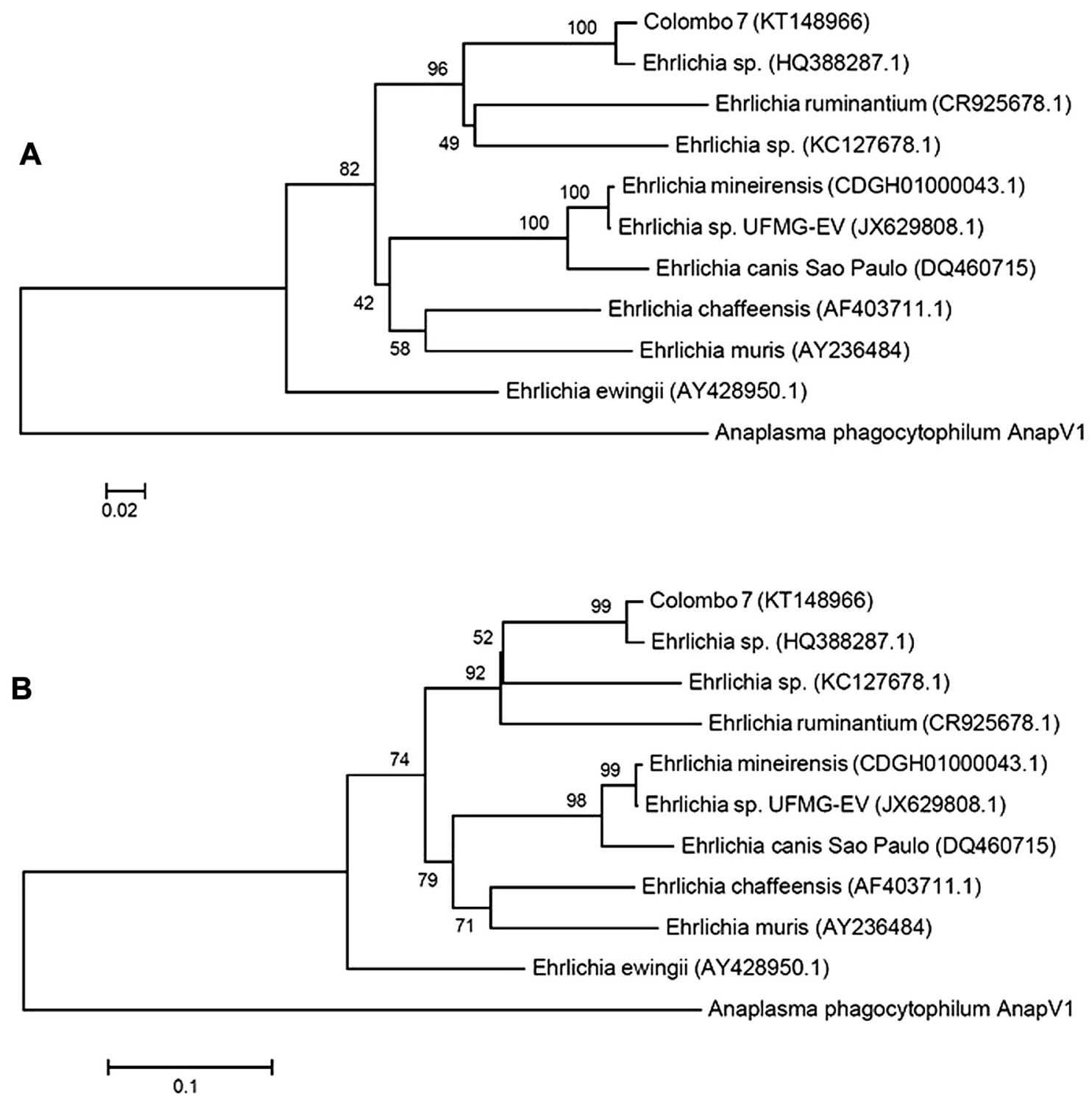

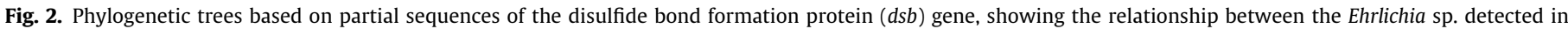

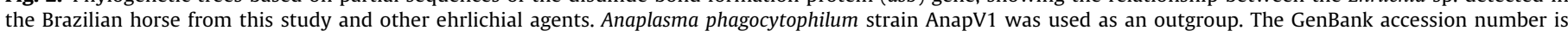

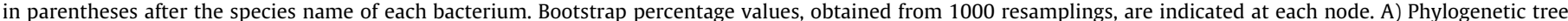

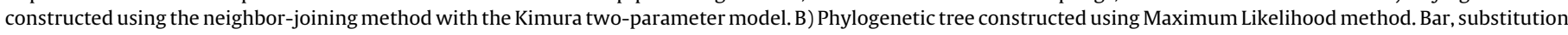
per nucleotide.

PCR in peripheral blood may also occur, as previously described in subclinically or chronically infected dogs [27].

Despite the commercial rapid ELISA kit used in the present study have been developed for screening dog samples [28], this kit has been previously used for screening Ehrlichia spp. in horses from Denmark, France, French Guyana, Africa, United States and Brazil [29-31]. In the present study, 27.4\% horses were seropositive for Ehrlichia spp. by using this commercial kit. However, when the three serological tests were combined the seroprevalence rate increased for $33.7 \%$, in agreement with previous studies which stated that the association of different methods for antibody detection of vector-borne pathogens improve sensitivity and specificity [32,33]. Considering that cell culture isolation of the Ehrlichia sp. infecting horses has not been performed yet, our findings suggest that a multi-modal approach should always be performed in horses as to increase the sensitivity of the infection detection and consequently the odds of finding and further characterizing this emerging ehrlichial agent.

Among factors associated to exposure, carthorses living in Alvorada do Sul City were 6.37 times more likely to present Ehrlichia spp. antibodies than carthorses living in Curitiba City $(p=0.0057)$. Moreover, carthorses infested by ticks were more likely to be Ehrlichia spp. seroreactive than carthorses without ticks $(p=0.0005)$. Unfortunately, only ticks from carthorses from Alvorada do Sul City were collected, with the majority identified as Amblyomma cajennense sensu lato $(69.4 \%, 127 / 183)$ and Dermacentor nitens (30\%, 55/183) [15]. A previous study reported that horses highly infested by Amblyomma americanum ticks were more commonly seropositive for Ehrlichia spp. [4]. Future efforts should focus on sampling, identification and detection of Ehrlichia DNA in ticks parasitizing horses in order to fully establish the putative tick vector of this Ehrlichia sp. infecting horses in Brazil. 
Finally, carthorses from low-income owners in the present study were mostly used for carrying recycling material in urban areas of Brazil, as previously described [15]. Therefore, Ehrlichia sp. infection in Brazilian carthorses may post public health concerns due to intimate contact with low-income owners.

\section{Conclusions}

Anti-Ehrlichia sp. antibodies and Ehrlichia DNA were detected in carthorses from Southern Brazil, which may post public health concerns due to intimate contact with low-income owners. This is the first report of a natural infection of this bacteria in horses from South America. Clinical signs and the tick vector remain unknown.

\section{Competing interests}

The authors have declared that no competing interests exist.

\section{Acknowledgments}

This study is part of the PhD degree of Thállitha S.W. Vieira at the Universidade Estadual de Londrina. This study was supported by Fundação Araucária do Paraná. The authors thanked IDEXX Laboratories Inc. for providing the SNAP ${ }^{\circledR} 4 \mathrm{Dx}{ }^{\circledR}$ kits.

\section{References}

[1] A. Cabezas-Cruz, M. Vancová, E. Zweygarth, M.F. Ribeiro, L. Grubhoffer, L.M Passos, Ultrastructure of Ehrlichia mineirensis, a new member of the Ehrlichia genus, Vet. Microbiol. 167 (2013) 455-458.

[2] J.S. Dumler, A.F. Barbet, C.P.J. Bekker, G.A. Dasch, G.H. Palmer, S.C. Ray, Y. Rikihisa, F.R. Rurangirwa, Reorganization of genera in the families Rickettsiaceae and Anaplasmataceae in the order Rickettsiales: unification of some species of Ehrlichia with Anaplasma, Cowdria with Ehrlichia and Ehrlichia with Neorickettsia, descriptions of six new species combinations and designation of Ehrlichia equi and 'HE agent' as subjective synonyms of Ehrlichia phagocytophila, Int. J. Syst. Evol. Microbiol. 51 (2001) 2145-2165.

[3] R.C. Carmichael, J.R. Duell, T.C. Holbrook, B.H. Herrin, C.M. Leutenegger, T.P. O'Connor, S.E. Little, Antibodies reactive to Ehrlichia spp. are common in Oklahoma horses, Vector Borne Zoonotic Dis. 14 (2014) 552-556.

[4] J.R. Duell, R. Carmichael, B.H. Herrin, T.C. Holbrook, J. Talley, S.E. Little, Prevalence and species of ticks on horses in Central Oklahoma, J. Med. Entomol. 50 (2013) 1330-1333.

[5] V.L. O’Nion, H.J. Montilla, B.A. Qurollo, R.G. Maggi, B.C. Hegarty, S.J. Tornquist, E.B. Breitschwerdt, Potentially novel Ehrlichia species in horses Nicaragua, Emerg. Infect. Dis. 21 (2015) 335-338.

[6] R.F.C. Vieira, T.S.W.J. Vieira, D.A.G. Nascimento, T.F. Martins, F.S. Krawczak, M.B. Labruna, R. Chandrashekar, M. Marcondes, A.W. Biondo, O. Vidotto, Serological survey of Ehrlichia species in dogs, horses and humans: zoonotic scenery in a rural settlement from southern Brazil, Rev. Inst. Med. Trop. (Sao Paulo) 55 (2013) 335-340.

[7] R.F.C. Vieira, A.W. Biondo, A.M.S. Guimaraes, A.P. Santos, R.P. Santos, L.H. Dutra, P.P.V.P. Diniz, H.A. Morais, J.B. Messick, M.B. Labruna, O. Vidotto, Ehrlichiosis in Brazil, Rev. Bras, Parasitol. Vet. 20 (2011) 1-12.

[8] R.Z. Machado, J.M.B. Duarte, A.S. Dagnone, M.P.J. Szabó, Detection of Ehrlichia chaffeensis in Brazilian marsh deer (Blastocerus dichotomus), Vet. Parasitol. 139 (2006) 262-266.

[9] L.S. Oliveira, K.A. Oliveira, L.C. Mourão, A.M. Pescatore, M.R. Almeida, L.G. Conceição, M.A. Galvão, C. Mafra, First report of Ehrlichia ewingii detected by molecular investigation in dogs from Brazil, Clin. Microbiol. Infect. 15 (2009) 55-56.

[10] C.E. Widmer, F.C. Azevedo, A.P. Almeida, F. Ferreira, M.B. Labruna, Tick-borne bacteria in free-living jaguars (Panthera onca) in Pantanal, Brazil, Vector Borne Zoonotic Dis. 11 (2011) 1001-1005.

[11] M.R. André, J.S. Dumler, D.G. Scorpio, R.H. Teixeira, S.M. Allegretti, R.Z. Machado, Molecular detection of tick-borne bacterial agents in Brazilian and exotic captive carnivores, Ticks Tick Borne Dis. 3 (2012) 247-253.

[12] A.P. Almeida, T.D. Souza, A. Marcili, M.B. Labruna, Novel Ehrlichia and Hepatozoon agents infecting the crab-eating fox (Cerdocyon thous) in southeastern Brazil, J. Med. Entomol. 50 (2013) 640-646.
[13] M.B. Labruna, C.E. Kerber, F. Ferreira, J.L.H. Faccini, D.T. De Waal, S.M. Gennari, Risk factors to tick infestations and their occurrence on horses in the state of São Paulo, Brazil, Vet. Parasitol. 97 (2001) 1-14.

[14] A.D. Alves, A.L. Melo, M.V. Amorim, A.M. Borges, L. Gaíva e Silva, T.F. Martins, M.B. Labruna, D.M. Aguiar, R.C. Pacheco, Seroprevalence of Rickettsia spp. in equids and molecular detection of 'Candidatus Rickettsia amblyommii' in Amblyomma cajennense sensu lato ticks from the Pantanal region of Mato Grosso, Brazil, J. Med. Entomol. 51 (2014) 1242-1247.

[15] T.S. Vieira, R.F. Vieira, M.A. Finger, D.A. Nascimento, P.M. Sicupira, L.H. Dutra, I. Deconto, I.R. Barros-Filho, P.T. Dornbusch, A.W. Biondo, O. Vidotto, Seroepidemiological survey of Theileria equi and Babesia caballi in horses from a rural and from urban areas of Paraná State, southern Brazil, Ticks Tick Borne Dis. 4 (2013) 537-541.

[16] T.S.W.J. Vieira, O. Vidotto, A.M. Guimarães, A.P. Santos, N.C. Nascimento, M.A.P. Finger, I.R. Barros-Filho, P.T. Dornbusch, A.W. Biondo, R.F.C. Vieira, J.B. Messick, Use of pan-hemoplasma PCR for screening horses highly exposed to tick bites from southern Brazil, Semina: Ciências Agrárias 36 (2015) 291-294.

[17] R. Chandrashekar, C.A. Mainville, M.J. Beall, T. O'Connor, M.D. Eberts, A.R. Alleman, S.D. Gaunt, E.B. Breitschwerdt, Performance of a commercially available in-clinic ELISA for the detection of antibodies against Anaplasma phagocytophilum Ehrlichia canis, and Borrelia burgdorferi and Dirofilaria immitis antigen in dogs, Am. J. Vet. Res. 71 (2010) 1443-1450.

[18] R. Chandrashekar, D. Daniluk, S. Moffitt, L. Lorentzen, J. Williams, Serologic diagnosis of equine borreliosis: evaluation of an in-clinic enzyme-linked immunosorbent assay (SNAP ${ }^{\circledR} 4 \mathrm{Dx}^{\circledR}$ ), Intern. J. Appl. Res. Vet. Med. 6 (2008) $145-150$.

[19] A.L. Johnson, T.J. Divers, Y.F. Chang, Validation of an in-clinic enzyme-linked immunosorbent assay kit for diagnosis of Borrelia burgdorferi infection in horses, J. Vet. Diagn. Invest. 20 (2008) 321-324.

[20] A.J. Birkenheuer, M.G. Levy, E.B. Breitschwerdt, Development and evaluation of a seminested PCR for detection and differentiation of Babesia gibsoni (Asian genotype) and B. canis DNA in canine blood samples, J. Clin. Microbiol. 41 (2003) 4172-4177.

[21] H. Inokuma, D. Raoult, P. Brouqui, Detection of Ehrlichia platys DNA in brown dog ticks (Rhipicephalus sanguineus) in Okinawa Island Japan, J. Clin. Microbiol. 38 (2000) 4219-4221.

[22] R.C. Edgar, MUSCLE: multiple sequence alignment with high accuracy and high throughput, Nucleic Acids Res. 32 (2004) 1792-1797.

[23] K. Tamura, G. Stecher, D. Peterson, A. Filipski, S. Kumar, MEGA6: molecular evolutionary genetics analysis version 6.0, Mol. Biol. Evol. 30 (2013) 2725-2729.

[24] A.G. Dean, K.M. Sullivan, M.M. Soe, OpenEpi: Open Source Epidemiol. Stat. Public Health (2015), http://www.openepi.com (accessed 10.19.15).

[25] A.J. Viera, J.M. Garrett, Understanding interobserver agreement: the kappa statistic, Fam. Med. 37 (2005) 360-363.

[26] R. Frutos, A. Viari, C. Ferraz, A. Morgat, S. Eychenié, Y. Kandassamy, I. Chantal, A. Bensaid, E. Coissac, N. Vachiery, J. Demaille, D. Martinez, Comparative genomic analysis of three strains of Ehrlichia ruminantium reveals an active process of genome size plasticity, J. Bacteriol. 188 (2006) 2533-2542.

[27] S. Harrus, M. Kenny, L. Miara, I. Aizenberg, T. Waner, S. Shaw, Comparison of simultaneous splenic sample PCR with blood sample PCR for diagnosis and treatment of experimental Ehrlichia canis infection, Antimicrob. Agents Chemother. 48 (2004) 4488-4490.

[28] R. Chandrashekar, C.A. Mainville, M.J. Beall, T. O’Connor, M.D. Eberts, A.R Alleman, S.D. Gaunt, E.B. Breitschwerdt, Performance of a commercially available in-clinic ELISA for the detection of antibodies against Anaplasma phagocytophilum, Ehrlichia canis, and Borrelia burgdorferi and Dirofilaria immitis antigen in dogs, Am. J. Vet. Res. 71 (2010) 1443-1450.

[29] M.G.B. Hansen, M. Christoffersen, L.R. Thuesen, M.R. Petersen, A.M. Bojesen, Seroprevalence of Borrelia burgdorferi sensu lato and Anaplasma phagocytophilum in Danish horses, Acta Vet. Scand. 52 (2010) 3-6.

[30] L. Maurizi, J.L. Marié, O. Aoun, C. Courtin, S. Gorsane, D. Chal, B. Davoust, Seroprevalence survey of equine lyme borreliosis in France and Sub-Saharan Africa, Vector Borne Zoonotic Dis. 10 (2010) 535-537.

[31] L. Maurizi, J.L. Marié, C. Courtin, S. Gorsani, D. Chal, B. Davoust, Seroprevalence survey of equine anaplasmosis in France and Sub-Saharan Africa, Clin. Microbiol. Infect. Dis. 15 (Suppl. 2) (2009) 68-69.

[32] M.D. Laurenti, M.V. de Santana Leandro Jr., T.Y. Tomokane, H.R.L. De Lucca, M. Aschar, C.S.F. Souza, R.M. Silva, M. Marcondes, V.L.R. da Matta, Comparative evaluation of the DPP ${ }^{\circledR}$ CVL rapid test for canine serodiagnosis in area of visceral leishmaniasis, Vet. Parasitol. 205 (2014) 444-450.

[33] R.G. Maggi, A.J. Birkenheuer, B.C. Hegarty, J.M. Bradley, M.G. Levy, E.B. Breitschwerdt, Comparison of serological and molecular panels for diagnosis of vector-borne diseases in dogs, Parasit. Vectors 7 (2014) 127. 